Case Report

\title{
Omalizumab for Urticarial Vasculitis: Case Report and Review of the Literature
}

\author{
Misbah Nasheela Ghazanfar ${ }^{1}$ and Simon Francis Thomsen ${ }^{1,2}$ \\ ${ }^{1}$ Department of Dermatology, Bispebjerg Hospital, 2400 Copenhagen NV, Denmark \\ ${ }^{2}$ Center for Medical Research Methodology, Department of Biomedical Sciences, University of Copenhagen, \\ 2200 Copenhagen N, Denmark
}

Correspondence should be addressed to Simon Francis Thomsen; simonfrancisthomsen@gmail.com

Received 10 May 2015; Revised 29 July 2015; Accepted 1 September 2015

Academic Editor: Michihiro Hide

Copyright (C) 2015 M. N. Ghazanfar and S. F. Thomsen. This is an open access article distributed under the Creative Commons Attribution License, which permits unrestricted use, distribution, and reproduction in any medium, provided the original work is properly cited.

\begin{abstract}
Urticarial vasculitis is characterised by inflamed itching or burning red patches or wheals that resemble urticaria but persist for greater than 24 hours. It is often idiopathic but is sometimes associated with collagen-vascular disease, particularly systemic lupus erythematosus. Treatment options include oral antihistamines, oral corticosteroids, dapsone, colchicine or hydroxychloroquine. We describe a male patient with urticarial vasculitis who was treated with omalizumab (anti-IgE) with convincing results and provide a review of previous reports of patients with urticarial vasculitis treated with omalizumab.
\end{abstract}

\section{Introduction}

Urticarial vasculitis is a variation of cutaneous vasculitis. Individual lesions appear as inflamed itching or burning red patches or wheals that resemble urticaria but persist for greater than 24 hours. Histopathologically, urticarial vasculitis presents as leukocytoclastic vasculitis with a perivascular mixed infiltrate of lymphocytes, neutrophils, and eosinophils, as well as fibrin deposits. Urticarial vasculitis is classified as normocomplementaemic or hypocomplementaemic based on the level of complement protein in blood. Although both subtypes are associated with typical symptoms such as angioedema, chest or abdominal pain, fever, and joint pain, the symptoms are more prominent in the hypocomplementaemic form, which is associated with systemic lupus erythematous. The majority of urticarial vasculitis cases are idiopathic $[1,2]$.

Recommended treatments for urticarial vasculitis are oral antihistamines and systemic immunosuppressant drugs such as oral corticosteroids, dapsone, colchicine, or hydroxychloroquine. While oral antihistamines might be useful for symptomatic relief of itch and for mild cutaneous disease without systemic involvement, most patients will need a course of oral corticosteroids to control exacerbation of cutaneous or systemic symptoms. Patients with hypocomplementaemic urticarial vasculitis with or without systemic lupus erythematous may have a more favourable response to dapsone, but the mechanism of action of dapsone is poorly understood and there are several adverse effects such as haemolysis, severe headache, and agranulocytosis. Monoclonal antibodies such as omalizumab (anti-IgE) have also been suggested for treatment of urticarial vasculitis [3]. An effective treatment for urticarial vasculitis is much needed as urticarial vasculitis impacts negatively the quality of life.

Omalizumab is a humanized anti-IgE monoclonal antibody that has recently been approved for treatment of chronic urticaria. Studies have shown that omalizumab significantly reduces the activity and symptoms of chronic urticaria. Also, omalizumab reduces the need for additional medication and improves quality of life. Clinical phases II and III studies have concluded that the ideal omalizumab dose for the treatment of chronic urticaria is $300 \mathrm{mg}$ s.c. administered once every four weeks [4-6].

Herein, we describe a male patient with urticarial vasculitis who was treated with omalizumab with convincing results. Furthermore, we review previous reports of patients with urticarial vasculitis treated with omalizumab. 


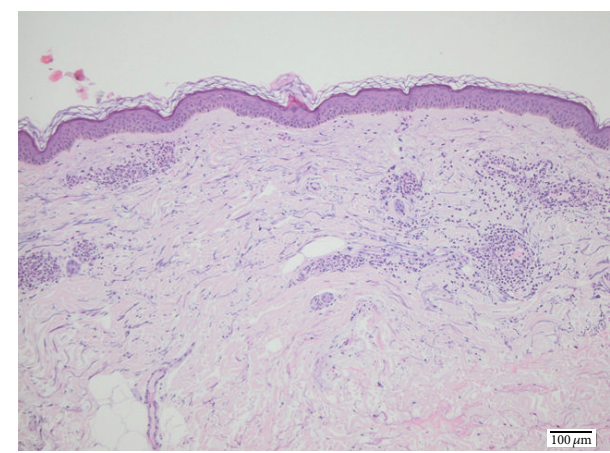

(a)

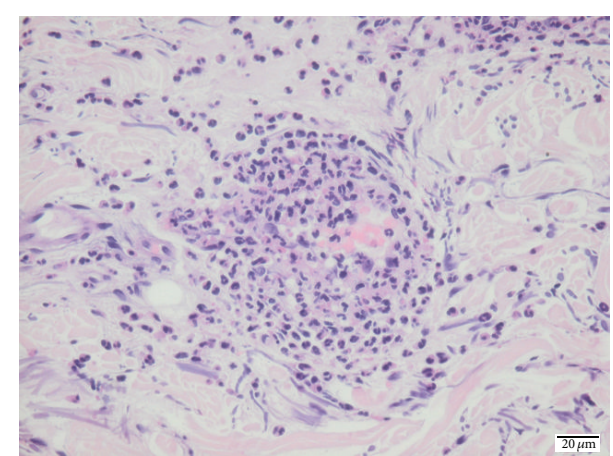

(b)

FIGURE 1: Histopathological sections of the patient showing leukocytoclastic vasculitis.

TABLE 1: Patients with urticarial vasculitis treated with omalizumab.

\begin{tabular}{lllll}
\hline Author & Year & Case & Dose of omalizumab & Effect of omalizumab \\
\hline Del Pozo et al. [3] & 2012 & $\begin{array}{l}\text { Female, aged 51, with SLE and urticarial vasculitis. } \\
\text { No improvement with oral corticosteroids, } \\
\text { antihistamines, and azathioprine }\end{array}$ & $\begin{array}{l}\text { Unknown: based on } \\
\text { weight and IgE }\end{array}$ & $\begin{array}{l}\text { Significant improvement } \\
\text { Lesions disappeared. No } \\
\text { hives or pain }\end{array}$ \\
\hline Varricchi et al. [7] & 2012 & $\begin{array}{l}\text { Female, aged 44, with asthma, Churg-Strauss } \\
\text { syndrome, and urticarial vasculitis. No } \\
\text { improvement with oral corticosteroids, } \\
\text { antihistamines, azathioprine, and cyclosporine }\end{array}$ & 300 mg s.c. every two \\
& & $\begin{array}{l}\text { Three females with chronic spontaneous urticaria } \\
\text { with autoimmune and pressure components plus } \\
\text { vasculitis. No improvement with antihistamines, } \\
\text { leukotriene receptor antagonists, and cyclosporine }\end{array}$ & $\begin{array}{l}\text { Significant improvement } \\
\text { of symptoms }\end{array}$ \\
\hline Díez et al. [8] & 2013 meeks (two patients) and & $\begin{array}{l}300 \text { mg s.c. every four } \\
\text { weeks (one patient) }\end{array}$ & $\begin{array}{l}\text { Remission of symptoms } \\
\text { in all three patients }\end{array}$ \\
\hline Sussman et al. [9] 2014 & $\begin{array}{l}\text { One patient, unknown gender and age, with } \\
\text { urticarial vasculitis }\end{array}$ & $\begin{array}{l}150 \mathrm{mg} \text { s.c. every four } \\
\text { weeks }\end{array}$ & $\begin{array}{l}\text { Remission of symptoms. } \\
\text { Details not given }\end{array}$ \\
\hline
\end{tabular}

\section{Case Presentation}

The patient was a 68-year-old man who unexpectedly developed severe, burning skin rashes clinically typical of urticarial vasculitis on his trunk, proximal upper extremities, and lower extremities during June 2014. The rashes consisted of erythematous and violaceous slightly ecchymotic infiltrated annular wheals lasting for more than 24 hours that resolved with slight postinflammatory hyperpigmentation. The patient had no angioedema and no extracutaneous manifestations such as fever, arthralgia, lymphadenopathy, uveitis, or serositis. Shortly before the onset of symptoms, he had a toe infection and received a short course of penicillin. The patient had a history of previous colon cancer for which he underwent surgery in 2008. Furthermore, he had total knee replacement surgery in 2012 due to arthritis, but he had no other previous history of rheumatic or collagen-vascular disease. He had basal cell carcinoma on the forehead in 2013. Routine blood tests including anti-cytoplasmic antibodies and anti-nuclear antibodies were normal, but he had slightly elevated secretion of protein in the urine. A skin biopsy revealed leukocytoclastic vasculitis with perivascular infiltrates primarily of neutrophils (Figure 1).

The patient was treated with oral prednisolone at a dose of $37.5 \mathrm{mg}$ once daily for one week and an improvement was observed. The patient was then advised to reduce the dosage of prednisolone to $25 \mathrm{mg}$ daily for three days and then to $12.5 \mathrm{mg}$ daily for one week and then slowly taper prednisolone altogether. After three months, the patient experienced relapse of skin rashes and was then treated with dapsone $50 \mathrm{mg}$ twice daily for one month but without significant improvement. In December 2014, the patient was switched to omalizumab $300 \mathrm{mg}$ s.c. once every four weeks, and already after one month a complete remission of the urticarial vasculitis and symptoms was observed. By July 2015, the patient is still being treated with omalizumab $300 \mathrm{mg}$ s.c. every four weeks with sustained remission and no apparent adverse effects. The patient was not treated with oral antihistamines throughout the course of the disease.

\section{Discussion}

Clinical phase studies have shown that omalizumab is safe and reduces disease activity in patients with chronic urticaria $[5,6]$. While there are no prospective clinical studies of omalizumab for urticarial vasculitis, a few case reports have shown that omalizumab might also be beneficial for this indication (Table 1). A case report by Del Pozo et al. described a female patient with systemic lupus erythematous and urticarial vasculitis. She was treated with oral antihistamines, oral corticosteroids, and azathioprine without improvement. She was then administrated omalizumab based on weight and IgE levels, which showed great improvement as her lesions disappeared [3]. Another case by Varricchi et al. described a female patient 
with asthma, Churg-Strauss syndrome, and urticarial vasculitis. She also had no symptomatic improvement while being treated with oral antihistamines, oral corticosteroids, or other immunosuppressants such as azathioprine and cyclosporine. She was then treated with omalizumab $300 \mathrm{mg}$ s.c. every two weeks as an add-on to antihistamines, oral corticosteroids, and immunosuppressants. After 6 months of treatment, the patient reported a significant improvement of her condition [7]. A Spanish case report involving three female patients with chronic spontaneous urticaria with autoimmune and pressure components and vasculitis also reported successful treatment with omalizumab [8]. Finally, an open-label study by Sussman et al. of patients with chronic urticaria involving also one patient with urticarial vasculitis noted that omalizumab was a sufficient treatment for the patients included in the study [9]. None of the patients included in these case studies experienced serious adverse effects during treatment.

Urticarial vasculitis with eruptive erythematous wheals resembles chronic urticaria, but the individual lesions usually last longer than in chronic urticaria. Symptoms are more frequently burning rather than itching and resolve with hyperpigmentation [1]. Several clinical studies have shown that omalizumab has great effect on chronic urticaria $[5,6]$ and while omalizumab is not the choice of treatment for urticarial vasculitis, it seems to have a beneficial effect on patients with urticarial vasculitis as reported herein and in the earlier published case reports. However, the mechanisms of action of omalizumab for urticarial vasculitis remain, in part, unresolved. Particularly, it is not known whether omalizumab is efficacious against both normocomplementaemic and hypocomplementaemic urticarial vasculitides. We did not measure levels of complement in blood in our patient.

\section{Conclusion}

Our report of successful treatment of urticarial vasculitis with omalizumab is important, as many patients with urticarial vasculitis cannot be treated successfully or experience significant side effects of the standard treatment. However, clinical trials with a greater number of patients with urticarial vasculitis that compare standard treatment with omalizumab are warranted.

\section{Conflict of Interests}

Simon Francis Thomsen is an advisory board member and speaker for Novartis.

\section{References}

[1] S. Chang and W. Carr, "Urticarial vasculitis," Allergy and Asthma Proceedings, vol. 28, no. 1, pp. 97-100, 2007.

[2] J. Venzor, W. L. Lee, and D. P. Huston, "Urticarial vasculitis," Clinical Reviews in Allergy and Immunology, vol. 23, no. 2, pp. 201-216, 2002.

[3] M. E. R. Del Pozo, N. P. M. Saenz, J. G. Vera, and J. L. Tiro, "Vasculitic urticaria treated with omalizumab. Case report," World Allergy Organization Journal, vol. 5, supplement 2, p. S106, 2012.
[4] S. Saini, K. E. Rosen, H.-J. Hsieh et al., "A randomized, placebocontrolled, dose-ranging study of single-dose omalizumab in patients with $\mathrm{H}_{1}$-antihistamine-refractory chronic idiopathic urticaria," Journal of Allergy and Clinical Immunology, vol. 128, no. 3, pp. 567.el-573.e1, 2011.

[5] T. Zuberbier, W. Aberer, R. Asero et al., "The EAACI/GA(2) LEN/EDF/WAO guideline for the definition, classification, diagnosis, and management of urticaria: the 2013 revision and update," Allergy, vol. 69, pp. 868-887, 2014.

[6] M. Maurer, K. Rosén, H. J. Hsieh et al., "Omalizumab for the treatment of chronic idiopathic or spontaneous urticaria," The New England Journal of Medicine, vol. 368, pp. 924-935, 2013.

[7] G. Varricchi, A. Detoraki, B. Liccardo et al., "Efficacy of omalizumab in the treatment of urticaria-vasculitis associated to Churg-Strauss syndrome: a case report," World Allergy Organization Journal, vol. 5, supplement 2, pp. S89-S90, 2012.

[8] L. S. Díez, L. M. Tamayo, and R. Cardona, “Omalizumab: therapeutic option in chronic spontaneous urticaria difficult to control with associated vasculitis, report of three cases," Biomedica, vol. 33, no. 4, pp. 503-512, 2013.

[9] G. Sussman, J. Hébert, C. Barron et al., "Real-life experiences with omalizumab for the treatment of chronic urticaria," Annals of Allergy, Asthma and Immunology, vol. 112, no. 2, pp. 170-174, 2014. 


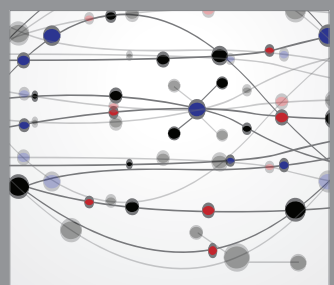

The Scientific World Journal
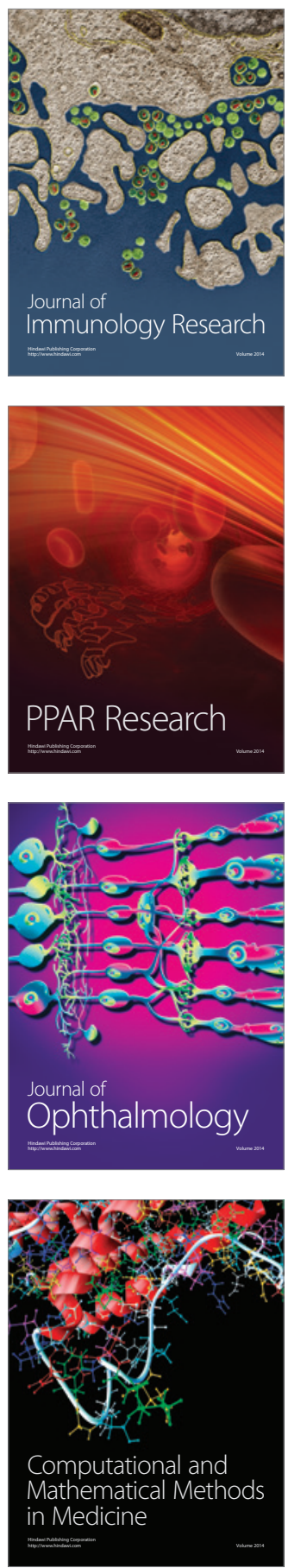

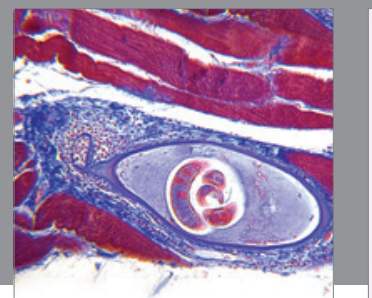

Gastroenterology

Research and Practice
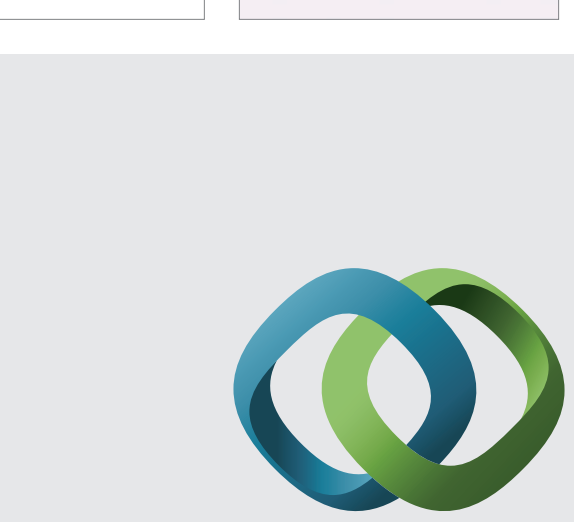

\section{Hindawi}

Submit your manuscripts at

http://www.hindawi.com
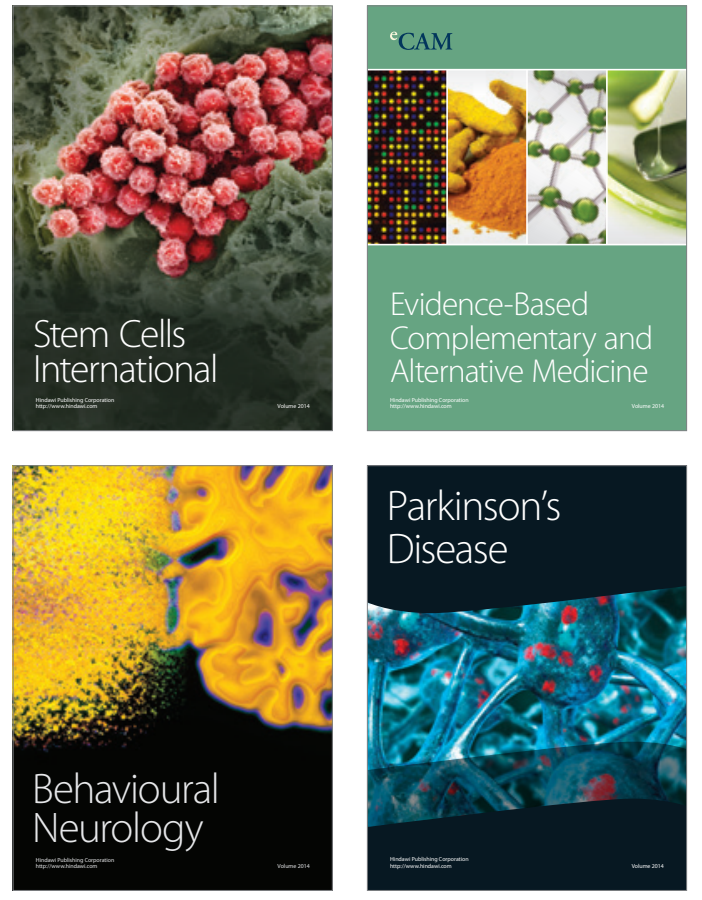
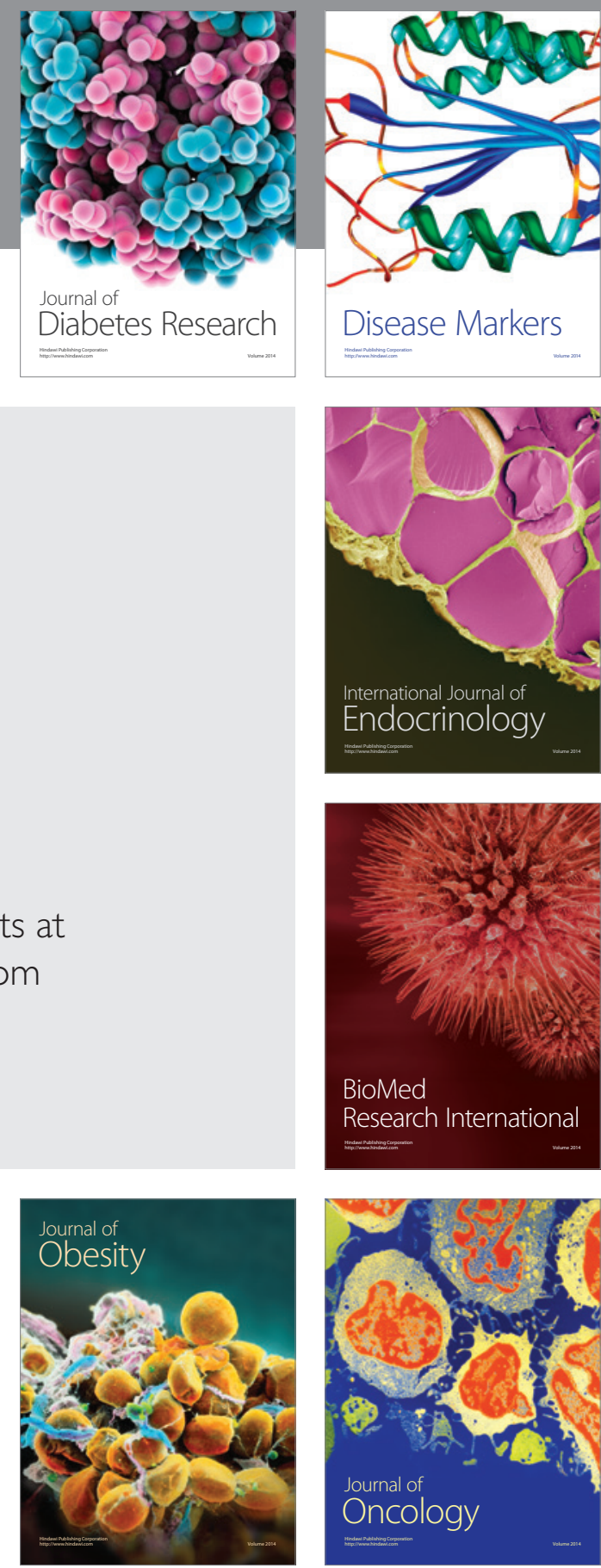

Disease Markers
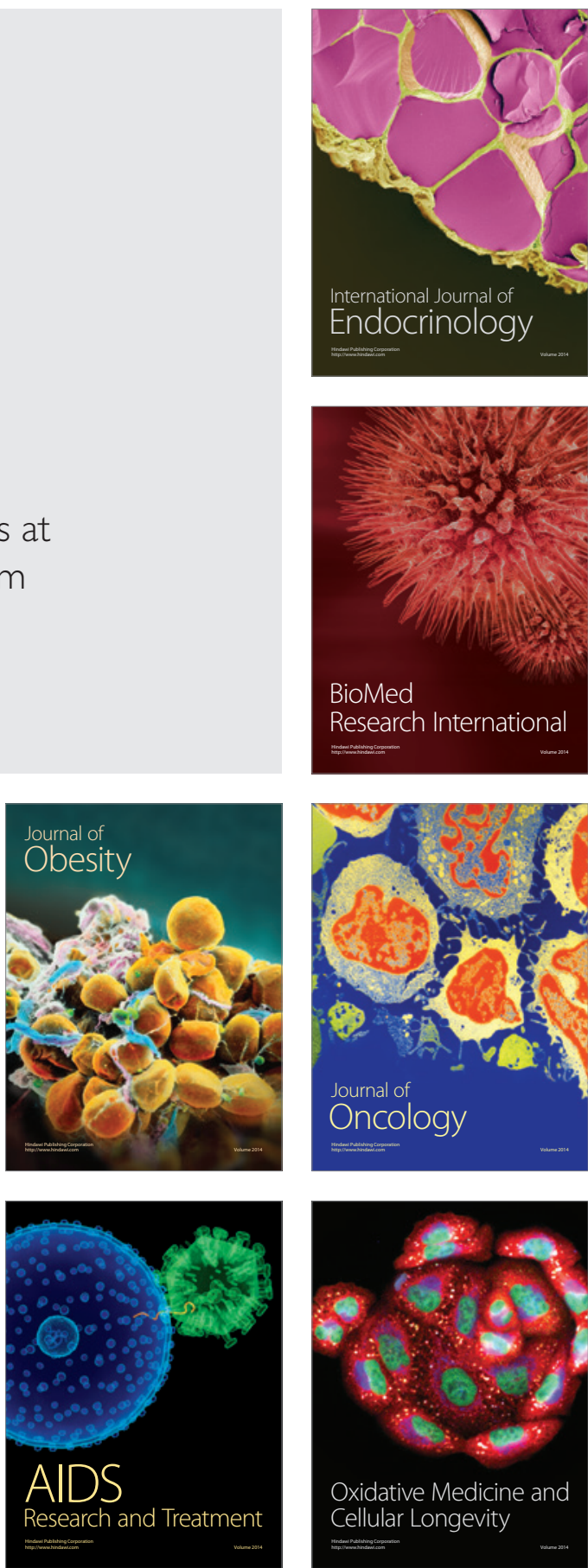